\title{
Cyclic Performance Tests of Si/MWCNT Composite Lithium Ion Battery Anodes at Different Temperatures
}

\author{
U. Tocoglu*, O. Cevher, H. Akbulut \\ Sakarya University, Engineering Faculty, Department of Metallurgical and Materials Engineering, \\ Esentepe Campus 54187, Turkey
}

\begin{abstract}
In this study silicon-multi walled carbon nanotube (Si-MWCNT) lithium ion battery anodes were produced and their electrochemical galvanostatic charge/discharge tests were conducted at various $\left(25^{\circ} \mathrm{C}, 35^{\circ} \mathrm{C}, 50^{\circ} \mathrm{C}\right)$ temperatures to determine the cyclic behaviors of anode at different temperatures. Anodes were produced via vacuum filtration and DC magnetron sputtering technique. Silicon was sputtered onto buckypapers to form composite structure of anodes. SEM analysis was conducted to determine morphology of buckypapers and Si-MWCNT composite anodes. Structural and phase analyses were conducted via X-ray diffraction and Raman Spectroscopy technique. CR2016 coin cells were assembled for electrochemical tests. Cyclic voltammetry test were carried out to determine the reversibility of reactions between anodes and reference electrode between $0.01-2.0 \mathrm{~V}$ potential window. Galvanostatic charge/discharge tests were performed to determine cycle performance of anodes at different temperatures.
\end{abstract}

DOI: $10.12693 /$ APhysPolA.127.1059

PACS: 77.55.df, 81.15.Cd, 82.47.Aa, 78.67.Sc, 61.48.De

\section{Introduction}

Lithium-ion batteries (LIBs) are known to play already the most important role in the powering of portable electronic devices. Applications of rechargeable LIBs in mobile and stationary power storage has generated numerous researches to improve their energy density, power density and cycling life [1-3]. (To minimize the $\mathrm{CO}$ and $\mathrm{CO}_{2}$ emissions from the burning of fossil fuels and meet the ever-growing need for high energy and high power, rechargeable electric storage devices for electrical (EV) and hybrid electrical vehicles (HEV) have attracted more and more attention on LIBs). Compared with most other battery technologies, LIBs have the advantages of high energy density, long cycle life, high voltage, and excellent rate capability. However, there are still many challenges for further development of LIBs sufficient for electrical transportation with high energy density, long cycling life, excellent rate capability, low cost, etc. For the case of anode material, commercial graphite anode shows excellent capacity retention during cycling of battery. Although graphite as the anode possesses high coulombic efficiency, good cycling stability and low cost, its theoretical capacity is only $372 \mathrm{~mA} \mathrm{hg}^{-1}$ which, clearly insufficient for powering of next generation electrical applications [4]. Silicon is the most attractive candidate since the possibility of forming $\mathrm{Li}_{22} \mathrm{Si}_{5}$ alloy ( $\left.\mathrm{Li} / \mathrm{Si}=4.4\right)$ according to the Li-Si phase diagram. (Si can also forms lower Li content Li-Si phases in the initial steps of silicon lithiation such as $\mathrm{Li}_{13} \mathrm{Si}_{4}(\mathrm{Li} / \mathrm{Si}=3.25), \mathrm{Li}_{7} \mathrm{Si}_{4}(\mathrm{Li} / \mathrm{Si}=1.75)$, and $\mathrm{Li}_{12} \mathrm{Si}_{7}$ $(\mathrm{Li} / \mathrm{Si}=1.71))$. Theoretically, $\mathrm{Li}_{22} \mathrm{Si}_{5}$ can deliver a specific capacity of $4200 \mathrm{~mA} \mathrm{~h} \mathrm{~g}^{-1}$, which is 10 times higher

${ }^{*}$ corresponding author; e-mail: utocoglu@sakarya.edu.tr

than the graphite electrode [5]. Despite advantages, volume variation during lithiation is the major drawback of Li-Si alloys as it can reach $300 \%$ of its original volume via $\mathrm{Li}_{22} \mathrm{Si}_{5}$ formation, whereas only $10 \%$ of volume variation is observed for $\mathrm{LiC}_{6}$. Volume variations caused by the lithiation of silicon leads the mechanical stress that causes cracking and pulverization of the anode which is responsible for loss of electrical contact between silicon particle thus low cyclability and rapid capacity fade [6]. Novel anode architectures have been suggested in order to solve the volume variation related problems of silicon anodes. Thin film and nano sized silicon anodes have been studied extensively but it is understood that they could not provide enough mechanical integrity during lithiation [7]. The superior mechanical properties of carbon nanotubes (CNTs) have received much attention, leading to many efforts to design materials that realize macro scale advantages through integrating nano scale composite structures. Core/shell ( $\mathrm{Si} / \mathrm{CNT})$ composite architecture has many advantages against the volume variations of silicon. The mechanical stresses could be absorbed by carbon nanotubes while the conductive carbon nanotube network provides the superior electrical conductivity. In this study it is aimed to produce carbon nanotube reinforced silicon anodes to enhance the electrochemical performance of silicon anodes. It is also aimed to test of cyclic performance of anodes at different temperatures of $25{ }^{\circ} \mathrm{C}, 35^{\circ} \mathrm{C}$ and $50^{\circ} \mathrm{C}$ to understand effect of temperature on the anode performance.

\section{Experimental}

Carbon nanotube papers (buckypaper) were produced from multiwalled carbon nanotubes (MWCNT) as substrate of sputtering process. Buckypaper production consist of three steps as follows; purification, functionalization and vacuum filtration. After buckypaper production 
step, DC magnetron sputtering technique was employed for composite electrode production. Silicon was sputtered onto buckypapers from silicon targets. DC power was chosen for sputtering process as $150 \mathrm{~W}$ with constant deposition time. Phase analysis and crystal structure investigations of composite anodes were carried out via XRD (Rigaku D/MAX 2000). Morphology analyses of composite anode structures were carried out via scanning electron microscopy (SEM) (Jeol JSM-6060 LV system). Coin type (CR2016) cells were assembled for electrochemical characterization of composite anodes. Composites anodes were used as working electrode and pure lithium foils were used as counter electrode. $1 \mathrm{M} \mathrm{LiPF}_{6}$ dissolved in a mixture of ethylene carbonate (EC) and diethyl carbonate (DEC) (1:1 by wt.) solution was chosen as the electrolyte. Galvanostatic charge/discharge tests were carried out by MTI Model BST8-MA electrochemical analyzer with constant current density between voltage ranges of $0.05-2.0 \mathrm{~V}$. Cyclic voltammetry analyses were carried out with Gamry Instruments Reference 3000 electrochemical work station between voltage ranges of $0.05-2.0 \mathrm{~V}$.

\section{Results and discussion}

Figure 1 shows XRD analysis results of nanocomposite anodes. No reflections except those of the carbon nanotube buckypaper substrate (002) were detected by XRD analysis of the sample. Thus, the deposited silicon is considered amorphous (a-Si). It is reported that the amorphous silicon seems better than crystalline silicon for electrochemical performance for the batteries since amorphous materials are more durable to volume expansions and have more open structure for $\mathrm{Li}^{+}$ion transportation [8-10]. Two unidentified peaks around 43 and $532 \theta$ degrees probably related with residual titanium oxide which is coming from titanium alloyed ultrasonic homogenization probe.

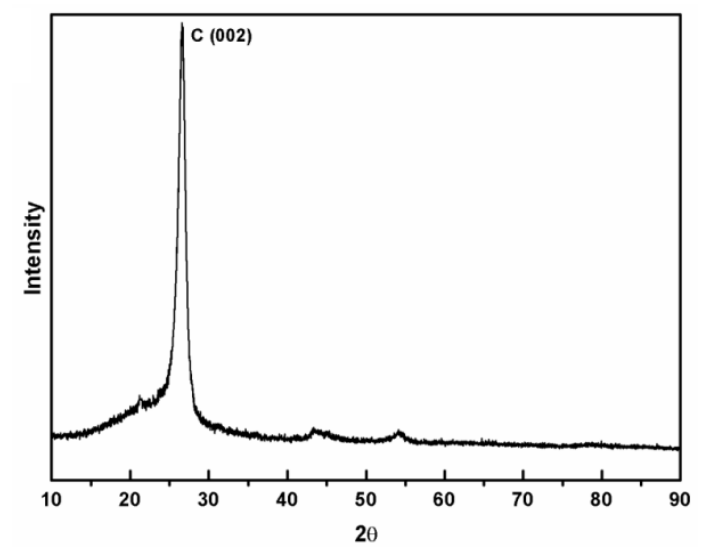

Fig. 1. XRD analysis result of nanocomposite $\mathrm{Si} / \mathrm{MWCNT}$ anodes.

As it can be seen obviously from Fig. 2a, silicon was deposited homogenously on carbon nanotubes. Composite structure consists of a thin silicon layer at top and carbon nanotube network under the silicon layer. Furthermore, it is understood from Fig. $2 \mathrm{~b}$ that porous structure which is provided by the buckypaper production route is almost preserved after silicon deposition. The porous structure provides the structural stability of anodes against the volume variation during the lithiation of silicon.
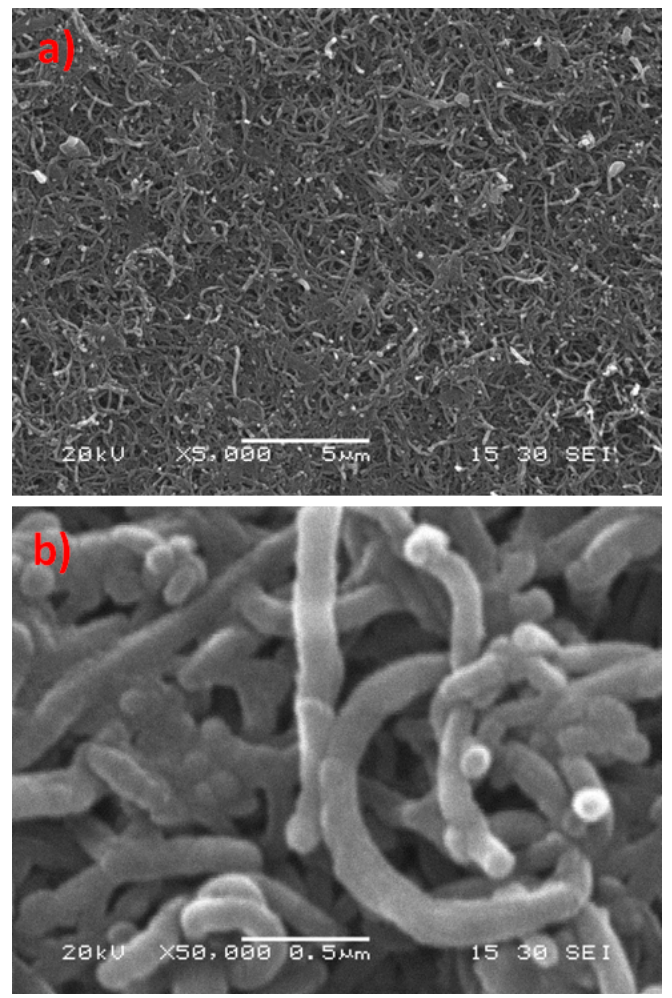

Fig. 2. SEM images of composite anodes produced with $150 \mathrm{~W}$ sputtering power in different magnifications of a) $\times 5000$, b) $\times 50000$.

The volume increment of silicon phase of anode could be hosted at pores and mechanical failure of anode could be prevented. Also porous structure provides greater surface area so the more efficient interaction could take place between electrodes and electrolyte [11].

Cyclic voltammogram of Si-MWCNT composite anodes in potential range of $0.01-2.0 \mathrm{~V}$ at scan rate $0.5 \mathrm{~m} \mathrm{~V} \mathrm{~s}^{-1}$ is given at the Fig. 3 . It could be deduced by the demonstration of cyclic voltammetry that a number of reversible reactions occur during cycling.

Two cathodic peak at $1.0 \mathrm{~V}$ and $0.55 \mathrm{~V}$ arise from the formation of solid electrolyte interphase (SEI) on the surface of electrodes due to the reduction of electrolyte, which leads huge capacity loss at first cycle [12]. The peaks which belong to SEI formation disappear at following cycles because of its irreversible nature. SEI is an electronic insulator passive layer and lithium ion conductor. The cathodic peak below the $0.3 \mathrm{~V}$ is a result of reversible lithiation reactions [13]. At anodic section of voltammogram, peaks at $0.3-0.4 \mathrm{~V}$ could be attributed 


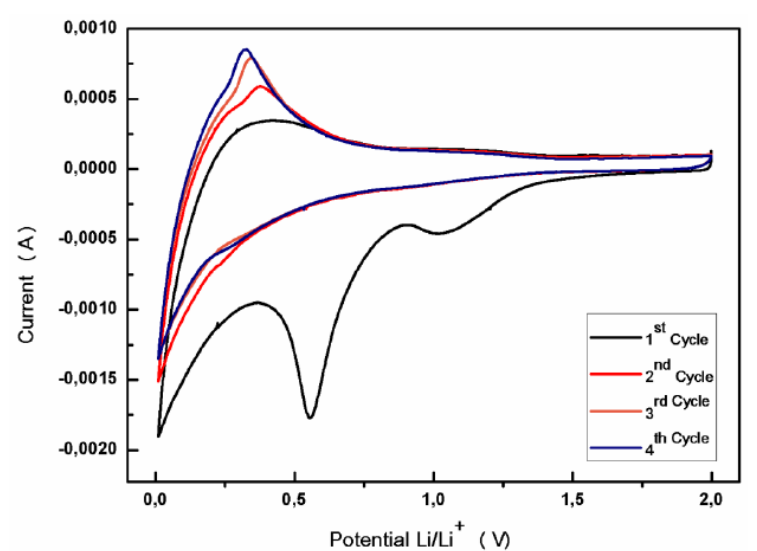

Fig. 3. Cyclic voltammogram of Si-MWCNT anodes.

to reversible decomposition reactions of lithium and silicon alloys [14]. At anodic section of voltammogram, enhancement of the anodic peak after first cycle indicates the activation of more silicon phases of the anode. From cyclic behavior diagram of anodes which is represented at Fig. 4, it can be concluded composite anodes have shown remarkable specific capacity values and moreover they also exhibited much more capacity values compared that of commercial graphite anodes even after 100 charge and discharge [15].

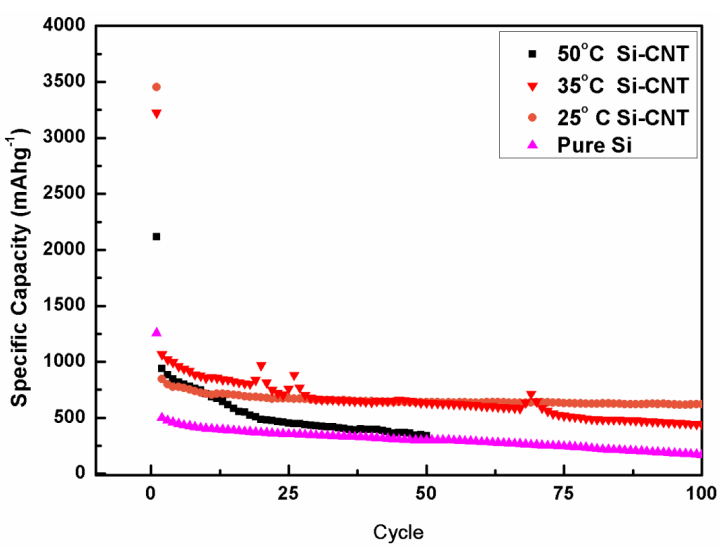

Fig. 4. Galvanostatic charge/discharge results of $\mathrm{Si} / \mathrm{MWCNT}$ anode at various elevated temperatures.

According to test results the test which is conducted at $25^{\circ} \mathrm{C}$ has showed the best cyclic performance among all composite anodes. At this temperature, after $100 \mathrm{cy}-$ cles $620 \mathrm{~mA} \mathrm{~h} \mathrm{~g}^{-1}$ capacity value was shown at the same time the most stable cyclic behavior was exhibited. After 100 cycles at $35^{\circ} \mathrm{C}$ the anode has shown $443 \mathrm{~mA} \mathrm{~h} \mathrm{~g}^{-1}$ capacity value. At that temperature, the capacity retention ability shows slight difference; however the capacity fading is was occurred faster when compared with the test which was conducted at $25{ }^{\circ} \mathrm{C}$. When temperature is risen to the $50^{\circ} \mathrm{C}$, composite silicon anodes were suffered with rapid capacity loss and failure of cells. After 50 galvanostatic charge/discharge cycles anodes have shown $341 \mathrm{~mA} \mathrm{~h}^{-1}$ reversible capacity but cell failure took place at subsequent cycles. The reason of worse cycle performance even failure at early stages of cycling is faster degradation of electrolyte. Due to the degradation of electrolyte, electrochemical between anode and cathode cannot take place and performance of anodes decreases.

\section{Conclusions}

Composite silicon/carbon nanotube anodes were successfully produced via magnetron sputtering technique. XRD analysis has showed that the silicon layer coated around the carbon nanotubes was amorphous which is beneficial for cycling performance of anode. SEM analysis has shown that anodes have porous structure and carbon nanotubes are wrapped around with thin silicon layer. CV results have proved the electrochemical reactions at cell and have shown the SEI formation which is responsible the capacity fade at first cycle. The effect of temperature is understood after galvanostatic charge/discharge test. The increment on temperature decreases the performance of anodes even causes cell failure.

\section{References}

[1] Y. Zhang, X.G. Zhang, H.L. Zhang, Z.G. Zhao, F. Li, C. Liu, H.M. Cheng, Electrochim. Acta 51, 4994 (2006).

[2] W.R. Liu, Z.Z. Guo, W.S. Young, D.T. Shieh, H.C. Wu, M.H. Yang, N.L. Wu, J. Power Sources 140, 139 (2005).

[3] N. Ding, J. Xu, Y. Yao, G. Wegner, I. Lieberwirth, C. Chen, J. Power Sources 192, 644 (2009).

[4] M. Thakur, M. Isaacson, S.L. Sinsabaugh, M.S. Wong, S.L. Biswal, J. Power Sources 205, 426 (2012).

[5] B. Bang, M.H. Kim, H.S. Moon, Y.K. Lee, J.W. Park, J. Power Sources 156, 604 (2006).

[6] B. Peng, F. Cheng, Z. Tao, J. Chen, J. Chem. Phys. 133, (2010).

[7] Z. Du, S. Zhang, T. Jiang, R. Lin, J. Zhao, Electrochimica Acta 74, 222 (2012).

[8] L.B. Chen, J.Y. Xie, H.C. Yu, T.H. Wang, J. Appl. Electrochem 39, 1157 (2009).

[9] V.A. Krivchenko, D.M. Itkis, S.A. Evlashin, D.A. Semenenko, E.A. Goodilin, A.T. Rakhimov, A.S. Stepanov, N.V. Suetin, A.A. Pilevsky, P.V. Voronin, Carbon 50, 1438 (2012).

[10] D.M. Chipara, A.C. Chipara, M. Chipara, Spectroscopy 26, 2 (10).

[11] M. Thakura, M. Isaacson, S. L. Sinsabaugh, M.S. Wonga, S.L. Biswala, Journal of Power Sources 205, 426 (2012).

[12] L. Yue, H. Zhong, L. Zhanga, Electrochim. Acta 76 , 326 (2012).

[13] G. Zhao, Y. Meng, N. Zhang, K. Sun, Mater. Lett. 76, 55 (2012).

[14] X. Shen, D. Mu, S. Chen, B. Xu, B. Wu, F. Wu, J. Alloy. Compd. 552, 60 (2013).

[15] B. Fuchsbichler, C. Stangl, H. Kren, F. Uhlig, S. Koller, J. Power Sources 196, 2889 (2011). 